\section{Should acellular pertussis vaccine be recommended to healthcare professionals?}

\author{
A vacina pertússis acelular deve ser recomendada \\ a profissionais de saúde?
}

\author{
¿La vacuna contra la tos ferina acelular se debe \\ recomendar a los profesionales de la salud?
}

\author{
${ }^{1}$ Faculdade de Ciências \\ Médicas da Santa Casa de \\ São Paulo, São Paulo, Brasil. \\ 2 Centro de Vigilância \\ Epidemiológica, Secretaria \\ Estadual de Saúde de São \\ Paulo, São Paulo, Brasil. \\ 3 Divisão de Vacinas, Sanofi \\ Pasteur, São Paulo, Brasil. \\ Correspondence \\ J. C. Moraes \\ Faculdade de Ciências \\ Médicas da Santa Casa de \\ São Paulo. \\ Rua Frederico von Martius \\ 88, São Paulo, SP 01548-010, \\ Brasil. \\ jcassiom@uol.com.br
}




\section{Introduction}

The terms health care professionals (HCPs) and health care workers (HCWs) are applied to a range of professional categories that includes physicians, nurses, assistants, physiotherapists, dentists, radiologists and technicians and other professional caregivers. Vaccination of these professionals is important to protect their health and reduce the risk of disease transmission to patients. In addition, vaccination reduces the economic impact of diseases associated with morbidity, work absences and loss of productivity due to presenteeism 1 .

In Brazil, a specific law (NR32) recommends that HCPs receive vaccines against diphtheria, tetanus, measles, mumps, rubella, hepatitis B and influenza and states: "available efficient vaccines against other biological agents to which workers are, or may become, exposed must be provided free of charge by the employer" 2 . However, HCP vaccination policies vary considerably between different countries $3,4,5,6,7,8,9,10,11,12,13,14,15,16,17,18,19$ and have changed over the two last decades due to new information on the epidemiological profile of pertussis and licensing of new safe and effective vaccines for use in adolescents and adults, such as the triple acellular (Tdap) vaccine that, besides protecting against diphtheria and tetanus, also protects against pertussis, and the quadruple vaccine against diphtheria, tetanus and pertussis combined with the inactivated polio vaccine (Tdap-IPV), already licensed in a number of countries $7,8,9,10,11,12,20,21,22,23,24,25,26,27$, $28,29,30,31,32,33,34,35,36,37,38,39,40,41,42,43,44,45,46,47,48,49$, $50,51,52,53,54,55,56,57$.

Acellular pertussis vaccines especially formulated for adolescents may contribute to a substantial reduction in the incidence of the disease 7,57,58,59,60,61,62. The Bordetella pertussis and diphtheria toxoid antigen content of these vaccines is lower than whole cell vaccines and the acellular vaccines recommended for children and they are as safe as the double-adult vaccine (dT) 7,9,23,24, $29,38,57,58,59,60,61,62$. It is currently recommended in several countries that adolescents and adults receive at least one booster of the $\mathrm{dT}$ vaccine in combination with the acellular pertussis (Tdap) vaccine $1,7,57,58,59,60,61,62$. Increasing numbers of developed nations prefer IPV, and Tdap-IPV or Tdap + IPV vaccines are specially indicated to people who are in contact with immunocompromised people or children immunized with the oral polio vaccine (OPV) ${ }^{1,14}$.

In this paper we review the current HCP vaccination recommendations, focusing on the pertussis acellular vaccines, through a data search of the PubMed (January/2000 to March/2012),
World Health Organization (WHO), Centers for Disease Control and Prevention (CDC), Pan American Health Organization (PAHO) and the Brazilian Ministry of Health websites based on the following key words: vaccine, pertussis, Bordetella pertussis, health professionals, and vaccination coverage.

\section{Pertussis clinical manifestations and diagnosis}

Pertussis, also known as "whooping cough", is an infectious disease with a high transmission rate (90\%) caused by the bacterium B. pertussis. Humans are the sole hosts of $B$. pertussis, and transmission occurs through contact with respiratory droplets from an infected individual. The incubation period of pertussis ranges from seven to 10 days, and the signs and symptoms of the disease vary according to age, vaccination condition, and time lapse since the last dose of the vaccine.

Pertussis typically occurs in the following three phases:

1) Catarrhal (one to two weeks): characterized by a runny nose, intermittent cough and low-grade fever. Symptoms can be not distinguished from other respiratory infections and the infected person is most contagious in this phase;

2) The paroxysmal phase (four to six weeks): characterized by paroxysms of intense coughing often followed by vomiting and a loud "whoop". These symptoms are more frequently seen in infants, the most vulnerable group with the highest rates of complications, such as pneumonia, weight loss, seizures, encephalopathy and eventually death;

3) Convalescence (two to six weeks): the most common symptom is a chronic cough.

Pertussis diagnosis is hindered due to the fact that signs and symptoms can not be differentiated from other respiratory diseases. Culture is considered the gold standard for pertussis diagnosis. However, its sensitivity is low, and many countries included PCR and serology to improve pertussis surveillance. Even in regions where these lab tests were introduced the true burden of pertussis is still underestimated 3,4,6,7,19,22,29.

\section{Pertussis vaccines}

Pertussis vaccines have been in use since the 1940 s, but are not recommended after seven years of age due to their reactogenicity. It is estimated that protection after natural infection and/ or pertussis vaccination lasts between 5 and 10 years. In locations with low vaccination coverage, 
circulation of B. pertussis in the community accounts for natural "boost". However, vaccination leads to a reduction in bacterial circulation and a subsequent loss of protection after natural infection, resulting in an increase in the incidence of the disease among teenagers and young adults, who become an significant source of infection of children 29,30,31,32,33,34,35,36,37,38,39,40.

Protection against the most serious forms of the disease offered by whole cell vaccines and acellular vaccines is greater in the early years after vaccination. Although the risk of hospitalization and death due to pertussis is lower in adults, the disease causes substantial morbidity in these groups and is one of the most common causes of continuous cough 22,24, 29,32,33,38,42. Separate vaccination of adolescents and adults became possible after the development and approval of specific vaccines for each group. The pertussis vaccines for adults licensed for use in Brazil are listed in Table 1. Only acellular vaccines with reduced quantity of diphtheria toxoid can be administered to adults, and they can be produced individually or in combination with IPV $7,8,9,10,11,12,13,14,29$.

During the last decade, the use of these vaccines for adolescents and adults, particularly those in contact with young babies, has been introduced in several countries 3,6,7,18,19,25,26,27,29,30, $31,32,38,43,46,49,52,57$.

\section{Vaccine recommendations for HCPs}

HCP vaccination recommendations vary according to country, vaccine availability, and to the risk estimates of the different preventable diseases immunization, the latter of which depends on epidemiological information 1,2,3,4,5,6,7,8,9,10,11,12, $13,14,15,16,17,18,19$. Most countries recommend the use of the influenza and hepatitis B vaccines; however, after the licensing of acellular vaccines for adolescents and adults, many countries have introduced these vaccines for HCPs. In the United States 1,7,8,9,10,11,12, Canada 13, various European countries 14,15, Australia 16,17 and some Latin America countries 18,19 , acellular pertussis vaccines combined with the tetanus and diphtheria toxoids (Tdap) and IPV standalone or with Tdap (Tdap-IPV) are already recommended for all or some HCPs 1,14 (Tables 2 and 3).

The inclusion of the acellular pertussis vaccine is due to an increase in the incidence of pertussis in certain European countries 28,29,30,31,32,33, $34,35,36,37,38,39,40$, the USA $1,78,9,10,11,12,21,24,25,26,27$, Canada 13,22,23 and Australia 16,17,41,42,43. In these regions pertussis currently affects all age groups, and incidence rates are particularly high in adolescents and young adults 36,38,43.

The reemergence of pertussis can be associated with a number of factors, including: incomplete protection provided by vaccines; waning of immunity after 5 to 20 years; introduction of new diagnostic tests, such as PCR and serologic tests; high perception of the disease during outbreaks and high notification rates of suspicious cases; circulation of new strains not covered by

\begin{tabular}{|c|c|c|c|c|}
\hline \multirow[b]{2}{*}{ Presentation } & \multicolumn{2}{|c|}{ Sanofi Pasteur } & \multicolumn{2}{|c|}{ GSK } \\
\hline & Tdap-IPV & Tdap & Tdap & Tdap-IPV \\
\hline Indicated age & $>3$ years and adults & $>4$ years and adults & $>4$ years and adults & $>4$ years and adults \\
\hline Pertussis toxoid $(\mu \mathrm{g})$ & 2.5 & 2.5 & 8.0 & 8.0 \\
\hline $\mathrm{PHA}(\mu \mathrm{g})$ & 5.0 & 5.0 & 8.0 & 8.0 \\
\hline PRN $(\mu \mathrm{g})$ & 3.0 & 3.0 & 2.5 & 2.5 \\
\hline FIM $2+3(\mu g)$ & 3.0 & 5.0 & - & - \\
\hline Diphtheria toxoid & $\geq 2 \mathrm{IU}(2 \mathrm{Lf})$ & $2 \mathrm{Lf}$ & $\geq 2 \mathrm{IU}(2.5 \mathrm{Lf})$ & $\geq 2 \mathrm{IU}(2.5 \mathrm{Lf})$ \\
\hline Tetanus toxoid & $\geq 20 \mathrm{IU}(5 \mathrm{Lf})$ & $5 \mathrm{Lf}$ & $\geq 20 \mathrm{IU}(5 \mathrm{Lf})$ & $\geq 20 \mathrm{IU}(5 \mathrm{Lf})$ \\
\hline \multicolumn{5}{|l|}{ Polio (D-Ag-U) } \\
\hline 1 & 40 & - & - & 40 \\
\hline 2 & 8 & - & - & 8 \\
\hline 3 & 32 & - & - & 32 \\
\hline
\end{tabular}

FIM: fimbria; PRN: pertactina; PHA: phytohaemagglutinin. 
Table 2

Acellular pertussis vaccines recommended for health care professionals (HCPs) by country and year.

\begin{tabular}{|c|c|c|c|}
\hline Country/Region & Reference & Year & Recommendation \\
\hline United States & 7 & 2005 & $\begin{array}{c}\text { Adults aged between } 19 \text { and } 64 \text { years and those with contact with babies }<12 \text { months } \\
\text { (parents, grandparents aged }<65 \text { years and HPCs), HCPs working in hospitals } \\
\text { or ambulatory care settings and have direct patient contact }\end{array}$ \\
\hline Canada & 13 & 2006 & All HCPs in contact with infants $\leq 18$ months \\
\hline World (World Health & 6 & 2011 & HCPs working with infants or immunocompromised people, especially in maternity \\
\hline Organization) & & & and pediatric units \\
\hline Germany & 14 & 2011 & All HCPs \\
\hline Austria & 14 & 2011 & Pediatricians and HCPs working in neonatal centers \\
\hline Belgium & 14 & 2011 & All HCPs \\
\hline France & 14 & 2011 & HCPs in direct patient contact \\
\hline Finland & 14 & 2011 & Pediatricians and HCPs in neonatal centers \\
\hline Netherlands & 14 & 2011 & All HCPs \\
\hline Luxembourg & 14 & 2011 & All HCPs \\
\hline Norway & 14 & 2011 & Pediatricians and HCPs in neonatal centers \\
\hline United Kingdom & 14 & 2011 & All HCPs \\
\hline Uruguay & 18 & 2012 & HCPs, especially those in direct contact with infants $<6$ months \\
\hline $\begin{array}{l}\text { Americas (Pan American } \\
\text { Health Organization) }\end{array}$ & 19 & 2012 & $\begin{array}{l}\text { Recommended for HCPs to prevent transmission to infants }<6 \text { months and } \\
\text { immunocompromised people }\end{array}$ \\
\hline
\end{tabular}

Table 3

Countries with recommendations for inactivated polio vaccine (IPV) use among health care professionals (HCPs) 14

\begin{tabular}{lc}
\hline Country & Recommendation \\
\hline $\begin{array}{l}\text { Austria } \\
\text { Cyprus }\end{array}$ & Recommended for specific HCP groups or health care settings \\
Finland & All HCPs \\
France & All HCPs \\
Germany & Mandatory for all HCPs \\
$\begin{array}{l}\text { Ireland } \\
\text { Lithuania }\end{array}$ & Recommended for specific HCP groups or health care settings \\
Luxembourg & Recommended for specific HCP groups or health care settings \\
Malta & All HCPs \\
Switzerland & All HCPs \\
United Kingdom & All HCPs \\
\hline
\end{tabular}

vaccines; and other unidentified factors. In developed countries, acellular pertussis vaccines were introduced after 1999, and nowadays the majority of pertussis cases are diagnosed in adolescents and adults that received acellular vaccines. There is no doubt that the duration of protection after acellular vaccines is limited. Furthermore, the low duration of protection after whole cell vaccines and natural infection was observed when vaccination was limited to these vaccines in the USA, Canada and Europe. The comparison of current trends between countries is limited because different countries use different vaccines, employ different vaccination schedules, have variable coverage rates and use different pertussis case research and reporting methods.

The recent reemergence of pertussis in Latin American countries that still use whole cell vac- 
cines has led to a great number of deaths. However, this reemergence cannot be explained by the introduction of acellular vaccines or new diagnostic tests, because access to these tests is not universal. Rather, it is probable that Latin American countries are experiencing a similar trend to that registered in developed countries over the last decade, where an age shift of pertussis was observed towards adolescents and adults due to high vaccination coverage rates among children. The availability of new diagnostic resources for pertussis, such as PCR and serology, has helped to identify pertussis as one of the main causes of prolonged cough illness in adults 22 and has shown that the disease may exist in mild or asymptomatic forms 33,51 . The large majority of pertussis cases are reported in young babies, but the disease may affect people of any age group, including the elderly 28,39,34,35,37,41,45,47,50,51,56.

Seroepidemiologic investigations of the disease conducted in different countries show that the annual incidence of pertussis in adolescents and young adults varies between 1 and $6 \% 34,35,37,40,44$ and that infection rates are greater among HCPs than in other professionals 24 .

\section{Pertussis in HCPs: risks to patients and health workers}

HCPs may contract pertussis and transmit the disease to their patients and hospital colleagues, thus causing disease outbreaks $1,8,10,11,15,16,45,48,63$, $64,65,66,67,68,69,70,71,72,73,74,75,76,77,78,79,80,81,82,83,84,85$ $86,87,88,89,90,91,92,93,94,95,96,97,98,99,100,101,102,103,104,105$. Residents and those working in emergency rooms are at risk of acquiring pertussis 24 ; however, other HCPs, such as nurses, physiotherapists and people who are in direct contact with patients are at greater risk of becoming infected $63,64,65,66,67,68$, $69,70,71,72,73,74,75,76,77,78,79,80,81,82,83,84,85,86,87,88,89,90$, 91,92,93,94,95,96,97,98,99,100,101,102,103,104,105. Adults generally develop a milder form of the disease than children, however morbidity and the chances of complications are high 1,7,21,22,23,24,29,30. In adults the disease generally lasts for four weeks, with $25 \%$ of patients developing complications 24 . It should be noted that even asymptomatic or mild cases may transmit B. pertussis to others, including family members $51,66,69,72,73,83,96$.

The majority of pertussis outbreaks associated with HCPs have been reported in pediatric hospitals $8,63,68,69,87,83,96$, particularly in neonatal care units and intensive care services $65,66,67,69,72,88,94,98,103$ with hospitalized infants in units that treat immunocompromised or institutionalized patients $64,95,104$. Recently, a pertussis outbreak was also detected among HCPs who worked in a laboratory specialized in pertussis diagnosis 96 .

Although pertussis hospital outbreaks involve only a small number of individuals, they may be very costly due to the recommended investigation and control measures that involve the temporary removal of the professionals from the working environment, the use of prophylactic antibiotics and laboratory tests of infected cases $65,66,67,68$, $69,70,71,72,73,74,75,76,77,78,79,80,81,82,83,84,85,86,87,88,89,90$, $91,92,93,94,95,96,97,98,99,100,101,102,103,104,105$, as well as problems associated with noncompliance with recommended prophylaxis 76,92,93,94,95,97,98,99.

Most of the information on pertussis in HCPs comes from the United States, Canada, Europe and Australia, where laboratory resources for the confirmation of cases in adults, such as PCR and specific serology, are more easily available 16,17,57, $58,59,60,63,64,65,66,67,68,69,70,71,72,73,74,75,76,77,81,82,83,84$, $85,86,87,88,89,90,91,92,93,94,95,97,98,99,100,101,102,103,104$.

In the United States, pertussis outbreaks in HCPs were reported more than three decades ago 105 and reports of pertussis outbreaks involving HCPs have become increasingly common since the 1990s, especially during pertussis epidemics which occur every three to four years even in vaccinated populations $10,11,66,67,67,68,69,70,71,72,73$, $74,75,76,77,78,79,80,81$.

The risk of contracting pertussis through contact with patients has been very well documented 15,16,17,21,31,61,62,65,66,67,68,69,70,71,72,74, 104,105. In 2003, in the United States, a single baby with pertussis transmitted the disease to $17 \mathrm{HCPs}$ that in turn transmitted it to 307 people 66 .

During an outbreak in Cincinnati, $2 \%$ of the employees (87 out of 3,764 ) of a pediatric hospital developed pertussis, leading to the following morbidities: 97\% (84/87) of the infected employees had a cough for over two weeks; $74 \%$ (64/87) had a paroxysmal cough; and $31 \%$ (27/87) suffered from post-cough vomits 80 .

Ten patients and five employees of a hospital in Atlanta developed pertussis during a period of only two months. A total of 630 of the 1,330 HCPs were treated with erythromycin prophylaxis and a half dose of the child acellular vaccine (DTaP) in an attempt to control the epidemic, since the specific adult formulation had still not been licensed at the time 21 .

In 2003, the investigation of a case of pertussis in a premature newborn hospitalized in an intensive care unit revealed that the index case was a 36 year-old nurse who had worked with a paroxysmal cough for three weeks, and was only removed from work after developing pneumothorax. During the investigation, it was discovered that four out of a total of 72 exposed health professionals also developed the disease 65 . 
In 2004, an investigation of a pertussis outbreak that affected six children born between 4 and 16 of June in Texas, identified 29 children under four months of age who met the clinical criteria for pertussis, of which 11 had had contact with a nurse who was later confirmed as having pertussis. This professional worked with cough and dyspnea symptoms while in contact with 113 babies, of which 11 (9.7\%) developed the disease 72 .

Since the symptoms of pertussis in adolescents and adults generally consists of an extensive cough without fever, it is not always easy to recognize the disease, and the majority of the HCPs maintain their usual activities during the maximum transmissibility phase, thus exposing patients and fellow workers to pertussis 16,17,63,64, $65,66,67,68,69,70,71,72,73,74,75,76,77,85,90,91,92,93,94,95,96,97$, $98,99,100,101,102,103,104,105$. The growth culture is considered the gold standard for pertussis diagnosis; however, test sensitivity is poor since $B$. pertussis exhibits a slow growth. In locations where the PCR test is not available, the disease is seldom recognized in adults and, therefore, outbreak control measures are seldom taken 68 . In addition, recommended hospital outbreak control measures are not always effectively implemented $65,69,72,73,74,75,76,81$.

In a study of a case involving four health professionals diagnosed with pertussis conducted in Atlanta, the average cough duration before the index case was identified varied between 11 and 25 days 65 .

Another study concluded that precaution measures (isolation and chemoprophylaxis) were inadequate in 17 out of 28 confirmed pertussis cases, resulting in the exposure of 355 HCPs, each of which exposed an average of nine other HCPs to the disease (variation 1 to 86). Adequate precautionary measures were adopted in a little more than one third of cases (11 out of a total of 28 cases) during another outbreak. A total of 355 HCPs were exposed to 17 patients with pertussis without any protection, and it was considered that exposure to pertussis would be "probably inevitable" in more than $80 \%$ of the contacts 69 .

In France, pertussis is not a disease that requires compulsory notification and approximately half of the notified pertussis cases are from hospitals where an HCP is affected 86 . Several pertussis intra-hospital transmission cases have also been reported in the last decade. In 1997, a 55 year-old nurse worked for five weeks with a cough until she was eventually diagnosed with pertussis. The investigation showed that nine out of 61 health professionals (15\%) who had been in contact with the index case had serological indications of recent pertussis infection 82 .
The investigation of a pertussis outbreak between November 2000 and March 2011 after confirmation of three cases among hospital health professionals revealed that 91 people were exposed to infected patients, including 77 HCPs, 12 patients and two patients' relatives, generating four additional pertussis cases 83 .

Another outbreak in a maternity center involving five HCPs led to 10 probable cases among a group of 101 HCPs who were exposed to the disease out of a total of 201 professionals that worked in the center and agreed to participate in the investigation. Only $60 \%$ of participants took the prescribed antibiotic, $85 \%$ of the suspects used masks, and only $46 \%$ used the mask correctly 85 . One of the reasons for noncompliance with prophylactic measures is the high rate of side effects associated with the use of macrolides (33\%) 84 . However, the main reason for noncompliance is a lack of awareness among HCPs of the risks the disease poses 71,81 .

\section{Cost implications of Pertussis outbreaks in hospitals}

Although pertussis outbreaks that occurred in hospital settings affected relatively few patients (between two and 17) and HCPs (between five and 13), the cost implications were substantial due to the need to investigate the presence of the disease in a large number of people, absenteeism and measures against pertussis 66,68,69,70,80,92.

During an outbreak in Cincinnati, 79 employees had to stay off work for at least five days and 622 people took antibiotics for 14 days 80 .

It is estimated that each pertussis case costs between US $\$ 164$ and US $\$ 357$, while the cost of controlling hospital outbreaks varies between US $\$ 19,500$ and US $\$ 195,000$, depending on the number of professionals exposed to the disease $66,68,69,70,92$

The estimated cost of managing the exposure of 355 HCPs in a tertiary care center for children in Cincinnati during a period of 20 months was US $\$ 69,770$, while vaccination of the professionals involved cost approximately US\$60,000 69

The cost of a pertussis outbreak involving HCPs in France was $€ 46,661$, of which $42 \%$ was due to loss of productivity 83 .

An estimate based on the direct and indirect costs (temporary work absence) associated with outbreak control suggested that HCP vaccination could decrease costs by $238 \%$ and reduce the chances of infection by $46 \% 66$. 


\section{Vaccine acceptance and the difficulties in implementing other prophylactic measures to prevent the spread of pertussis}

Despite recommendations, many HCPs do not get vaccinated $77,87,88,89,90,91,92,93$ because they wrongly believe that infection or vaccination during childhood provides permanent protection $87,88,89,90,91,92,93$. Studies also show that the following main factors are associated with low vaccine coverage in HCPs: low perception of risk; lack of specific knowledge of vaccines; unawareness of vaccination recommendations and legislation and lack of orientation by the health authorities (Table 4). Lack of access to vaccines in the workplace due to cost factors also hinder compliance with vaccination recommendations. This is the case not only with new vaccines, such as Tdap and Tdap-IPV, but also for those vaccines traditionally recommended for HCPs 8,16,17,88,89.

Low coverage and incomplete vaccination regimens put the exposed individual at risk and generate expenses for employees and for the employers in the form of laboratory tests, treatment and/or immunoprophylaxis. Despite this, prophylactic measures to avoid infections are not always adopted in a timely manner $63,64,65,66,67,68$, $69,70,71,72,73,74,75,76$.

Lack of knowledge of the recommendation regarding the use of chemoprophylaxis after exposure to pertussis is a relevant issue even in countries where vaccines for HCPs are recommended 17,76,80,81,82,92.

An investigation into the knowledge and attitudes with regard to pertussis vaccination performed in the USA with 63 HCPs showed that only $19 \%$ were aware that pertussis is a mandatory notifiable disease and half (52\%) were aware of pertussis vaccination recommendations for HCPs in force in the USA since 2006. Almost half $(48 \%)$ were not aware of the need to prescribe prophylactic antibiotics for people exposed to pertussis, and only $22 \%$ knew that the patients' close contacts should also be tested 75 .

In a study conducted in France, physicians were more aware of occupational vaccinations than other HCPs and pediatricians were the best informed regarding the need to protected against flu and pertussis 87. In Germany 91 and Australia 97 misconceptions about pertussis were more prevalent among nursing health professionals. It should be pointed out that these professionals have greater direct contact with high risk children, and have been more frequently identified as primary cases in pertussis outbreaks reported in neonatal units 65,66,67,68,69,72,94,98.

In a study that involved almost 2,000 HCPs in Sweden in 2007 71, only 13\% of interviewees planned to take the acellular pertussis vaccine. The main factor associated with vaccine refusal was the belief that vaccination against pertussis during childhood provides permanent protection.

The difficulties involved in achieving compliance with pertussis vaccination of HCPs in some countries have led to discussions regarding compulsory vaccination 10,11,16,17. In Germany, $68.4 \%$ of 1,215 HCPs supported mandatory vaccination for HCPs, however, acceptations of mandatory vaccination was lower among nurses, the group with lower immunization coverage rates 91 .

Even in some regions in Australia, where the pertussis vaccination is compulsory for health professionals, more than one third of professionals believed that they remained protected after vaccination during childhood 97 .

\section{Pertussis in Brazil}

In Brazil, acellular pertussis vaccines for adolescents and adults (Tdap and Tdap-IPV) are only available in private clinics and, although recommended by the Brazilian Society of Immunization and by Medical Associations, they have not yet been included in the NR32 for HCPs $2,3,4,5$.

Factors associated with acceptance and refusal of acellular pertussis vaccines by health care professionals (HCPs) $17,75,81,87,88,89,90,91$.

\begin{tabular}{l}
\hline Acceptance \\
\hline $\begin{array}{l}\text { 1. Received a recommendation to take vaccination from a physician } \\
\text { 2. Awareness of CDC recommendation for pertussis vaccination }\end{array}$ \\
$\begin{array}{ll}\text { for HCPs } & \text { 1. Lack of a personal recommendation for vaccination } \\
\text { 3. Encouraged to take vaccination by coworker } & \text { 2. Misconception that vaccine received previously protects for life } \\
\text { 4. Belief that HCPs may spread pertussis to patient and family } & \text { 3. Low perception of the personal risks of contracting pertussis }\end{array}$
\end{tabular}

CDC: Centers for Disease Control and Prevention. 
Pertussis incidence rates in Brazil are very low compared with many countries and most cases are reported in infants under six months of age $3,4,54,55,56$. Pertussis diagnosis is generally carried out using clinical criteria and with or without the culture method 3,4,54,55,56. Although culture is considered the gold standard for pertussis diagnosis, it rarely gives positive results when the classic criterion for pertussis (a cough lasting for more than two weeks) is adopted. Pertussis is seldom suspected in adults and it is generally not possible to confirm diagnosis through growth culture 54,55,56. Lack of data does not mean that the disease does not occur, and recent studies in Latin American countries 45,46,47,48,49,50,51,52, $53,54,55,56$, including Brazil 45,56, have shown that young adults (19 to 39 years of age) are a source of infection to children 56 . With regard to transmission among HCPs, only one publication concerning a teaching hospital in the State of São Paulo was found 106. The number of pertussis cases and associated deaths has risen in Brazil. In 2011, there were 2,257 cases and 55 deaths 3 . In the State of São Paulo, 913 cases and 23 deaths were recorded, corresponding to about $40 \%$ of pertussis cases and deaths registered in Brazil 4 . It is important to emphasize that RT-PCR pertussis diagnosis has only been introduced in the State of São Paulo 3,4.

\section{The main issues associated with the Tdap and Tdap-IPV vaccines}

The Tdap and Tdap-IPV vaccines recommended for HCPs are safe and their reactogenicity profile is similar to that of the dT and dT-IPV vaccines 7 , $8,9,16,29,100,101,102,103,104,107,108,109,110,111,112,113,114$, $115,116,117,118,119,120$. Fewer local reactions were reported among Tdap or Tdap-IPV recipients compared with those who received Tdap or Tdap-IPV. The majority of adverse events were local reactions, similar to those observed in children who received four doses of DTaP 7,62,107,108,109,113.

There is little information on the efficacy of Tdap and Tdap-IPV vaccines for HCPs. However, immune response is excellent and, based on efficacy data in adolescents and adults, it is estimated that vaccine effectiveness is almost $80 \% 7,23$. Seroconversion occurs after only one week in more then $40 \%$ of individuals and high seroconversion rates (> 90\%) against diphtheria, tetanus, pertussis and poliovirus have been reported after two to four weeks 107,108.

Tdap and Tdap-IPV vaccines were recommended only for adolescents and young adults ( $<64$ years of age) with an interval of at least two years after the use of $\mathrm{dT} 7$; however, there is cur- rently no minimum interval between $\mathrm{dT}$ and Tdap or Tdap-IPV 9,114,120 and data confirms that Tdap can be used safely in the elderly, albeit with a reduction in antibody levels 115,116.

The Advisory Committee on Immunization Practices (ACIP) recommends that adults aged $\geq 65$ years (including HCPs) who have or who anticipate having close contact with an infant < 12 months of age and who have not previously received dTpa should receive a single dose of Tdap to protect against pertussis, regardless of the interval since the last tetanus or diphtheriatoxoid containing vaccine ${ }^{9}$. European studies of Tdap-IPV also showed that this vaccine can be safely used after dT 107,108.

When necessary (e.g., travel or epidemics), Tdap or Tdap-IPV vaccines may be given to pregnant women, preferentially after the first trimester of pregnancy 9,12,13,18,19,114.

It is estimated that protection lasts for 5 to 10 years 110,111,112,113,117,118,119; however, until now, only a few countries recommend redosing of these vaccines 31 . Recent studies confirmed that a dTpa vaccine can be given 5 to 10 years after the previous dose in adults immunized with the same product $117,118,119$.

Several studies have provided evidence that Tdap and Tdap-IPV may be given simultaneously with other vaccines whether they contain a live agent or not (influenza, triple viral, hepatitis B and HPV) 7,9,109,114.

\section{Conclusions}

Pertussis has reemerged in a number of countries and is considered a risk to HCPs, their patients and family members.

HCPs play an important role in suspecting, reporting and treating pertussis. Pertussis outbreaks in health care facilities have been detected in different countries. Measures to investigate, treat and control pertussis clusters are not very effective and generate a huge waste of resources that could be much better employed in disease prevention.

HCP pertussis immunization benefits both the community and the individual, since it reduces the risk of contraction and transmission of the disease.

Little information on the risk and acceptance of pertussis vaccines by HCPs is available in Brazil, and it is crucial to disseminate information on the risks of this disease and the benefits of vaccination, and improve pertussis surveillance with introduction of new diagnostic tests (RTPCR and serology). 
Considering the close association between vaccine acceptance and recommendations that laypeople receive from HCPs, the latter should receive continuing education on this subject to enable them to provide information on the benefits offered by the vaccines as recommended by the Medical Associations.

\section{Resumen}

El propósito de este artículo es describir los recientes cambios en la epidemiología y políticas de vacunación para la prevención de la tos ferina en los profesionales de la salud. Los autores realizaron un estudio de los artículos publicados en PubMed, sitios como SciELO, de la OMS, OPS, CDC y Ministerio de Salud de Brasil con las siguientes palabras clave: vacunas contra la tos ferina $y$ profesionales de la salud. La vacunación de los trabajadores de la salud contra la tos ferina es recomendada por la OMS, la OPS, CDC y por las autoridades sanitarias de 9 países europeos, de Australia, Hong Kong, Singapur, Costa Rica, Argentina y Uruguay, y en algunos países es obligatoria. En Brasil, se ha identificado un solo artículo sobre la vacunación de los trabajadores de la salud contra la tos ferina, sin embargo, frente al resurgimiento de la enfermedad con un gran número de hospitalizaciones y muertes en 2011, consideramos que es necesario revisar la política pública de vacunación de los profesionales de la salud, especialmente si tienen contacto con niños pequeños.

Vacuna contra las Tos Ferina; Personal de Salud;

Riesgos Laborales
Considering the difficulties in diagnosing the disease and delays in the implementation of measures to control the dissemination of $B$. pertussis in hospitals, this study recommends greater attention on the part of health authorities with regard to the control and management of pertussis.

\section{Contributors}

J. C. Moraes and L. F. Bricks contributed to project design and the drafting and final approval of this article. T. Carvalhanas contributed to project design and the critical review and final approval of this article.

\section{Acknowledgments}

The authors are grateful to the Department of Social Medicine of the Faculty of Medical Sciences of the Santa Casa de São Paulo.

\section{Conflicts of interests}

L. F. Bricks works in Sanofi Pasteur, Brazil. 


\section{References}

1. New York State Department of Health. NYSDOH health advisory: recommendations for vaccination of health care personnel (HCP). http://www. health.state.ny.us/prevention/immunization/ health_care_personnel/docs/2008_vaccination of_health_care_personnel.ppt (accessed on 09/ Nov/2009).

2. Ministério do Trabalho e Emprego. Norma regulatória no 32. http://www.mte.gov.br/legislacao/ normas_regulamentadoras/nr_32.pdf (accessed on 09/Nov/2011).

3. Ministério da Saúde. Imunização. http://portal. saude.gov.br/portal/saude/profissional/area. cfm?id_area $=1448$ (accessed on 04/Dec/2012).

4. Divisão de Doenças Respiratórias, Centro de Vigilância Epidemiológica. Imunização. http://www. cve.saude.sp.gov.br/htm/cve_im.html (accessed on 04/Dec/2012).

5. Sociedade Brasileira de Imunizações. Vacinação. http://www.sbim.org.br/vacinacao/ (accessed on 09/Nov/2011).

6. World Health Organziation. Pertussis vaccines: WHO position paper recommendations. Vaccine 2011; 29:2355-6.

7. Kretsinger K, Broder KR, Cortese MM, Joyce MP, Ortega-Sanchez I, Lee GM, et al. Preventing tetanus, diphtheria, and pertussis among adults: use of tetanus toxoid, reduced diphtheria toxoid and acellular pertussis vaccine recommendations of the Advisory Committee on Immunization Practices (ACIP) and recommendation of ACIP, supported by the Healthcare Infection Control Practices Advisory Committee (HICPAC), for use of Tdap among health-care personnel. MMWR Recomm Rep 2006; 55(RR-17):1-37.

8. Immunization of health-care personnel: recommendations of the Advisory Committee on Immunization Practices (ACIP). MMWR Morb Mortal Wkly Rep 2011; 60(RR07):1-45.

9. Committee on Infectious Diseases. Additional recommendations for use of tetanus toxoid, reducedcontent diphtheria toxoid, and acellular pertussisvaccine (Tdap). Pediatrics 2011; 128:809-12.

10. Miller BL, Ahmed F, Lindley MC, Wortley PM. US hospital requirements for pertussis vaccination of healthcare personnel, 2011. Infect Control Hosp Epidemiol 2011; 32:1209-12.

11. Weber DJ, Consoli SA, Sickbert-Bennett E, Rutala WA. Assessment of a mandatory tetanus, diphtheria, and pertussis vaccination requirement on vaccine uptake over time. Infect Control Hosp Epidemiol 2012; 33:81-3.

12. Committee on Obstetric Practice. ACOG Committee Opinion N. 521: update on immunization and pregnancy: tetanus, diphtheria, and pertussis vaccination. Obstet Gynecol 2012; 119:690-1.

13. North Vancouver School District. Pertussis (whooping cough) - important letter from Vancouver Coastal Health. http://www.nvsd44.bc.ca/Up dates/HealthInformation.aspx (accessed on 12/ April/2012).
14. Maltezou HC, Wicker S, Borg M, Heininger U, Puro $\mathrm{V}$, Theodoridou M, et al. Vaccination policies for health-care workers in acute health-care facilities in Europe. Vaccine 2011; 29:9557-62.

15. Wicker S, Rose MA. Health care workers and pertussis: an underestimated issue. Med Klin $(\mathrm{Mu}$ nich) 2010; 105:882-6.

16. Helms C, Leask J, Robbins SC, Chow MY, McIntyre P. Implementation of mandatory immunisation of healthcare workers: observations from New South Wales, Australia. Vaccine 2011; 29:2895-901.

17. Seale H, Leask J, Raina MacIntyre C. Do they accept compulsory vaccination? Awareness, attitudes and behavior of hospital health care workers following a new vaccination directive. Vaccine 2009; 27:3022-5.

18. Ministerio de Salud Pública. Cambios en certificado esquema de vacunación. http://www.msp.gub. uy/uc_6061_1.html (accessed on 27/Mar/2012).

19. Pan American Health Organization. Epidemiological alerts and reports. Epidemiological alert: pertussis (whooping cough), 2 march 2012. http:// new.paho.org/hq/index.php?option=com_conten t\&task=view\&id=6483\&Itemid=2291 (accessed on 28/Mar/2012).

20. World Health Organization. Pertussis. http://www. who.int/topics/pertussis/en/ (accessed on 26/ Dec/2011).

21. Shefer A, Dales L, Nelson M, Werner B, Baron R, Jackson R. Use and safety of acellular pertussis vaccine among adult hospital staff during an outbreak of pertussis. J Infect Dis 1995; 171:1053-6.

22. Senzilet LD, Halperin SA, Spika JS, Alagaratnam M, Morris A, Smith B, et al. Pertussis is a frequent cause of prolonged cough illness in adults and adolescents. Clin Infect Dis 2000; 32:1691-7.

23. Greenberg DP, Doemland M, Bettinger JA, Scheifele DW, Halperin SA, Waters V, et al. Epidemiology of pertussis and Haemophilus influenzae type $b$ disease in Canada with exclusive use of a diphtheria-tetanus-acellular pertussis-inactivated poliovirus-Haemophilus influenzae type b pediatric combination vaccine and an adolescent-adult tetanus-diphtheria-acellular pertussis vaccine: implications for disease prevention in the United States. Pediatr Infect Dis J 2009; 28:521-8.

24. Campins-Martí M, Cheng HK, Forsyth K, Guiso N, Halperin S, Huang LM, et al. Recommendations are needed for adolescent and adult pertussis immunisation: rationale and strategies for consideration. Vaccine 2001; 20:641-6.

25. Healy CM, Rench MA, Baker CJ. Implementation of cocooning against pertussis in a high-risk population. Clin Infect Dis 2011; 52:157-62.

26. Washington State Departament of Health. Prevention and community health. Imunization \& child profile office. http://www.doh.wa.gov/cfh/immu nize/documents/pertupdate.pdf (accessed on 20/ Mar/2012). 
27. Communicable Disease Epidemiology and Immunization Section, King County, Government. Issue brief - prevention of pertussis in infants, January 2012. https://www.kingcounty.gov/healthser vices/health/communicable/providers/ /media/ health/publichealth/documents/communicable/ advisory110921.ashx/ (accessed on 28/Mar/2012).

28. Pebody RG, Gay NJ, Giammanco A, Baron S, Schellekens J, Tischer A, et al. The seroepidemiology of Bordetella pertussis infection in Western Europe Source. Epidemiol Infect 2005; 133:159-71.

29. Guiso N. Bordetella pertussis and pertussis vaccines. Clin Infect Dis 2009; 49:1565-9.

30. Guiso N, Liese J, Plotkin S. The global pertussis initiative: meeting report from the fourth regional roundtable meeting, France, 14-15 April, 2010. Hum Vaccin 2011; 7:481-8.

31. Euvacnet. Pertussis. http://www.euvacnet.org (accessed on 14/Nov/2011).

32. Lasserre A, Laurent E, Turbelin C, Hanslik T, Blanchon T, Guiso N. Pertussis incidence among adolescents and adults surveyed in general practices in the Paris area, France, May 2008 to March 2009. Euro Surveill 2011; 16:19783.

33. de Greeff SC, Mooi FR, Westerhof A, Verbakel JM, Peeters MF, Heuvelman CJ, et al. Pertussis disease burden in the household: how to protect young infants. Clin Infect Dis 2010; 50:1339-45.

34. de Greeff SC, de Melker HE, van Gageldonk PG, Schellekens JF, van der Klis FR, Mollema L, et al. Seroprevalence of pertussis in The Netherlands: evidence for increased circulation of Bordetella pertussis. PLoS One 2010; 5: e14183.

35. Kretzschmar M, Teunis PF, Pebody RG. Incidence and reproduction numbers of pertussis: estimates from serological and social contact data in five European countries. PLoS Med 2010; 7:e1000291.

36. Wiese-Posselt M, Hellenbrand W. Changes to the varicella and pertussis immunisation schedule in Germany 2009: background, rationale and implementation. Euro Surveill 2010; 15:19548.

37. Riffelmann M, Koesters K, Saemann-Ischenko G, Schmitt HJ, Wirsing von Koenig CH. Antibodies to pertussis antigens in pediatric health care workers. Pediatr Infect Dis J 2002; 21:381-3.

38. Zepp F, Heininger U, Mertsola J, Bernatowska E, Guiso N, Roord J, et al. Rationale for pertussis booster vaccination throughout life in Europe. Lancet Infect Dis 2011; 11:557-70.

39. Crespo I, Cardeñosa N, Godoy P, Carmona G, Sala MR, Barrabeig I, et al. Epidemiology of pertussis in a country with high vaccination coverage. Vaccine 2011; 29:4244-8.

40. Juanes JR, Gil A, González A, Arrazola MP, SanMartín M, Esteban J. Seroprevalence of pertussis antibody among health care personnel in Spain. Eur J Epidemiol 2004; 19:69-72.

41. Quinn HE, McIntyre PB. Pertussis epidemiology in Australia over the decade 1995-2005-trends by region and age group. Commun Dis Intell 2007; 31:205-15.
42. Jardine A, Conaty SJ, Lowbridge C, Staff M, Vally $\mathrm{H}$. Who gives pertussis to infants? Source of infection for laboratory confirmed cases less than 12 months of age during an epidemic, Sydney, 2009. Commun Dis Intell 2010; 34:116-21.

43. New South Wales Government. Pertussis. http:// www.health.nsw.gov.au/data/diseases/pertussis. asp (accessed on 11/Aug/2011).

44. Rendi-Wagner P, Tobias J, Moerman L, Goren S, Bassal R, Green M, et al. The seroepidemiology of Bordetella pertussis in Israel: estimate of incidence of infection. Vaccine 2010; 28:3285-90.

45. Kowalzik F, Barbosa AP, Fernandes VR, Carvalho PR, Avila-Aguero ML, Goh DY, et al. Prospective multinational study of pertussis infection in hospitalized infants and their household contacts. Pediatr Infect Dis J 2007; 26:238-42.

46. Ulloa-Gutierrez R, Avila-Aguero ML. Pertussis in Latin America: current situation and future vaccination challenges. Expert Rev Vaccines 2008; 7:1569-80.

47. Romanin V, Salvay MC, Man C, Mistchenko A, Gentile A. A B. pertussis outbreak in a pediatric hospital. Rev Hosp Niños B Aires 2005; 47:211-6.

48. Hozbor D, Mooi F, Flores D, Weltman G, Bottero D, Fossati S, et al. Pertussis epidemiology in Argentina: trends over 2004-2007. J Infect 2009; 59:225-31.

49. Vizzotti C. Epidemiological alert - alert number 1: alert for pertussis increased cases, January 25, 2012. http://www.msal.gov.ar/images/stories/ alertas_epidemiologia/2012/alerta-1-tos-convul sa-2012.pdf (accessed on 23/Feb/2012).

50. Beltrán Silva S, Cervantes Apolinar Y Cherry JD, Conde González C, Gentile A, et al. Consensus on the clinical and microbiologic diagnosis of Bordetella pertussis, and infection prevention. Expert Group on Pertussis Vaccination. Salud Pública Méx 2011; 53:57-65.

51. Perret C, Viviani T, Peña A, Abarca K, Ferrés M. Source of infection in young infants hospitalized with Bordetella pertussis. Rev Med Chil 2011; 139:448-54.

52. Departamento de Inmunizaciones, Subsecretaria de Salud Pública, Gobierno de Chile. Ordinario B27 no 4006, November 28, 2011. 52. [Reemplazo de la vacuna DTP (célula inteira) por dTpa (vacuna acelular)]. http://www.colegiodeenfermeras.cl/ Ord.pdf (accessed on 27/Mar/2012).

53. Duarte LSM, Moreno J, Gracia M, Realpe ME, Daza GLP. Estado de portadores de Bordetella pertussis en adolescentes de 12 a 19 años en el departamento del Tolima, Colombia, 2007. Investig Andin 2008; 10:7-26.

54. Centro de Vigilância Epidemiológica. Informe técnico. Situação epidemiológica atual da coqueluche - cenário global. Boletim Epidemiológico Paulista 2012; 9:26-35.

55. Freitas AC, Okano V, Pereira JCR. Pertussis booster vaccine for adolescents and young adults in São Paulo, Brazil. Rev Saúde Pública 2011; 45:1062-71. 
56. Baptista PN, Magalhães VS, Rodrigues LC. The role of adults in household outbreaks of pertussis. Int J Infect Dis 2010; 14:e111-4.

57. Halperin SA, Smith B, Russell M, Scheifele D, Mills E, Hasselback P, et al. Adult formulation of a five component acellular pertussis vaccine combined with diphtheria and tetanus toxoids and inactivated poliovirus vaccine is safe and immunogenic in adolescents and adults. Pediatr Infect Dis J 2000; 19:276-83.

58. Collins CL, Salt P, McCarthy N, Chantler T, Lane L, Hemme F, et al. Immunogenicity and safety of a low-dose diphtheria, tetanus and acellular pertussis combination vaccine with either inactivated or oral polio vaccine as a pre-school booster in UK children. Vaccine 2004; 22:4262-9.

59. Pichichero ME, Rennels MB, Edwards KM, Blatter MM, Marshall GS, Bologa M, et al. Combined tetanus, diphtheria, and 5-component pertussis vaccine for use in adolescents and adults. JAMA 2005; 293:3003-11.

60. Grimpel E, von Sonnenburg F, Sänger R, Abitbol V, Wolter JM, Schuerman LM. Combined reducedantigen-content diphtheria-tetanus-acellular pertussis and polio vaccine (dTpa-IPV) for booster vaccination of adults. Vaccine 2005; 23:3657-67.

61. Sandora TJ, Pfoh E, Lee GM. Adverse events after administration of tetanus-diphtheria-acellular pertussis vaccine to healthcare workers. Infect Control Hosp Epidemiol 2009; 30:389-91.

62. Kirkland KB, Talbot EA, Decker MD, Edwards KM. Kinetics of pertussis immune responses to tetanus-diphtheria-acellular pertussis vaccine in health care personnel: implications for outbreak control. Clin Infect Dis 2009; 49:584-7.

63. Centers for Disease Control and Prevention (CDC). Outbreaks of pertussis associated with hospitals: Kentucky, Pennsylvania, and Oregon, 2003. MMWR Morb Mortal Wkly Rep 2005; 54:67-71.

64. Boulay BR, Murray CJ, Ptak J, Kirkland KB, Montero J, Talbot EA. An outbreak of pertussis in a hematology-oncology care unit: implications for adult vaccination policy. Infect Control Hosp Epidemiol 2006; 27:92-5.

65. Bryant KA, Humbaugh K, Brothers K, Wright J, Pascual FB, Moran J, et al. Measures to control an outbreak of pertussis in a neonatal intermediate care nursery after exposure to a healthcare worker. Infect Control Hosp Epidemiol 2006; 27:541-5.

66. Calugar A, Ortega-Sánchez IR, Tiwari T, Oakes L, Jahre JA, Murphy TV. Nosocomial pertussis: costs of an outbreak and benefits of vaccinating health care workers. Clin Infect Dis 2006; 42:981-8.

67. Vranken P, Pogue M, Romalewski C, Ratard R. Outbreak of pertussis in a neonatal intensive care unit-Louisiana, 2004. Am J Infect Control 2006; 34:550-4.

68. Baggett HC, Duchin JS, Shelton W, Zerr DM, Heath J, Ortega-Sanchez IR, et al. Two nosocomial pertussis outbreaks and their associated costs - King County, Washington, 2004. Infect Control Hosp Epidemiol 2007; 28:537-43.
69. Daskalaki I, Hennessey P, Hubler R, Long SS. Resource consumption in the infection control management of pertussis exposure among healthcare workers in pediatrics. Infect Control Hosp Epidemiol 2007; 28:412-7.

70. Zivna I, Bergin D, Casavant J, Fontecchio S, Nelson S, Kelley A, et al. Impact of Bordetella pertussis exposures on a Massachusetts tertiary care medical system. Infect Control Hosp Epidemiol 2007; 28:708-12.

71. Goins WP, Schaffner W, Edwards KM, Talbot TR Healthcare workers' knowledge and attitudes about pertussis and pertussis vaccination. Infect Control Hosp Epidemiol 2007; 28:1284-9.

72. Centers for Disease Control and Prevention Hospital-acquired pertussis among newbornsTexas, 2004. MMWR Morb Mortal Wkly Rep 2008; 57:600-3.

73. Shah SI. Importance of vaccinations for close contacts and caregivers. Am Fam Physician 2008; 77:1664

74. Calderon M, Feja KN, Ford P, Frenkel LD, Gram A, Spector D, et al. Implementation of a pertussis immunization program in a teaching hospital: an argument for federally mandated pertussis vaccination of health care workers. Am J Infect Control 2008; 36:392-8.

75. Staes CJ, Gesteland PH, Allison M, Mottice S, Rubin M, Shakib JH, et al. Urgent care providers' knowledge and attitude about public health reporting and pertussis control measures: implications for informatics. J Public Health Manag Pract 2009; 15:471-8.

76. Leekha S, Thompson RL, Sampathkumar P. Epidemiology and control of pertussis outbreaks in a tertiary care center and the resource consumption associated with these outbreaks. Infect Control Hosp Epidemiol 2009; 30:467-73.

77. Miller BL, Kretsinger K, Euler GL, Lu PJ, Ahmed F. Barriers to early uptake of tetanus, diphtheria and acellular pertussis vaccine (Tdap) among adultsUnited States, 2005-2007. Vaccine 2011; 29:3850-6.

78. Goins WP, Edwards KM, Vnencak-Jones CL, Rock MT, Swift M, Thayer V, et al. A comparison of 2 strategies to prevent infection following pertussis exposure in vaccinated healthcare personnel. Clin Infect Dis 2012; 54:938-45.

79. Lindley MC, Lorick SA, Spinner JR, Krull AR, Mootrey GT, Ahmed F, et al. Student vaccination requirements of U.S. health professional schools: a survey. Ann Intern Med 2011; 154:391-400.

80. Christie CD, Glover AM, Willke MJ, Marx ML, Reising SF, Hutchinson NM. Containment of pertussis in the regional pediatric hospital during the Greater Cincinnati epidemic of 1993. Infect Control Hosp Epidemiol 1995; 16:556-63.

81. Top KA, Halperin BA, Baxendale D, MacKinnonCameron D, Halperin SA. Pertussis immunization in paediatric healthcare workers: knowledge, attitudes, beliefs, and behaviour. Vaccine 2010; 28:2169-73. 
82. Gehanno JF, Pestel-Caron M, Nouvellon M, Caillard JF. Nosocomial pertussis in healthcare workers from a pediatric emergency unit in France. Infect Control Hosp Epidemiol 1999; 20:549-52.

83. Ward A, Caro J, Bassinet L, Housset B, O’Brien JA, Guiso N. Health and economic consequences of an Outbreak of pertussis among healthcare workers in a hospital in France. Infect Control Hosp Epidemiol 2005; 26:288-92.

84. Giugliani C, Vidal-Trecaqn G, Traore S, Blanchard H, Spiridon G, Rollot F, et al. Feasibility of azithromycin prophylaxis during a pertussis outbreak among healthcare workers in a university hospital in Paris. Infect Control Hosp Epidemiol 2006; 27:626-9.

85. Vanjak D, Delaporte MF, Bonmarin I, Levardon M, Fantin B. Cases of pertussis among healthcare workers in a maternity ward: management of a health alert. Med Mal Infect 2006; 36:151-6.

86. Bonmarin I, Poujol I, Levy-Bruhl D. Nosocomial infections and community clusters of pertussis in France, 2000-2005. Euro Surveill 2007; 12:E11-2.

87. Hees L, Afroukh N, Floret D. Vaccination coverage among health care workers in the pediatric emergency and intensive care department of Edouard Herriot hospital in 2007, against influenza, pertussis, varicella, and measles. Arch Pediatr 2009; 16:14-22.

88. Loulergue P, Moulin F, Vidal-Trecan G, Absi Z, Demontpion C, Menager C, et al. Knowledge, attitudes and vaccination coverage of healthcare workers regarding occupational vaccinations. Vaccine 2009; 27:4240-3.

89. Duong M, Mahy S, Binois R, Buisson M, Piroth L, Chavanet P. Vaccination coverage of healthcare professionals in an infectious diseases department. Med Mal Infect 2011; 41:135-9.

90. Wicker S, Zielen S, Rose MA. Attitudes of healthcare workers toward pertussis vaccination. Expert Rev Vaccines 2008; 7:1325-8.

91. Wicker S, Marckmann G, Poland GA, Rabenau HF. Healthcare workers' perceptions of mandatory vaccination: results of an anonymous survey in a German University Hospital. Infect Control Hosp Epidemiol 2010; 31:1066-9.

92. Westra TA, de Vries R, Tamminga JJ, Sauboin CJ, Postma MJ. Cost-effectiveness analysis of various pertussis vaccination strategies primarily aimed at protecting infants in the Netherlands. Clin Ther 2010; 32:1479-95.

93. Crameri S, Heininger U. Successful control of a pertussis outbreak in a university children's hospital. Int J Infect Dis 2008; 12:e85-7.

94. Alexander EM, Travis S, Booms C, Kaiser A, Fry NK, Harrison TG, et al. Pertussis outbreak on a neonatal unit: identification of a healthcare worker as the likely source. J Hosp Infect 2008; 69:131-4.

95. Baugh V, McCarthy N. Outbreak of Bordetella pertussis among oncology nurse specialists. Occup Med (Lond) 2010; 60:401-5.

96. Miyashita N, Kawai Y, Yamaguchi T, Ouchi K, Kurose K, Oka M. Outbreak of pertussis in a university laboratory. Intern Med 2011; 50:879-85.
97. Peadon E, Cooper C. Whooping cough: are healthcare workers putting children at risk? J Paediatr Child Health 2007; 43:398-402.

98. Paterson JM, Sheppeard V. Nosocomial pertussis infection of infants: still a risk in 2009. Commun Dis Intell 2010; 34:440-3.

99. Greenberg D, Bamberger E, Ben-Shimol S, Gershtein R, Golan D, Srugo I. Pertussis is under diagnosed in infants hospitalized with lower respiratory tract infection in the pediatric intensive care unit. Med Sci Monit 2007; 13:CR475-80.

100. Weber DJ, Rutala WA, Schaffner W. Lessons learned: protection of healthcare workers from infectious disease risks. Crit Care Med 2010; 38(8 Suppl):S306-14.

101. Greer AL, Fisman DN. Use of models to identify cost-effective interventions: pertussis vaccination for pediatric health care workers. Pediatrics 2011; 128:e591-9.

102. Hoffait M, Hanlon D, Benninghoff B, Calcoen S. Pertussis knowledge, attitude and practices among European health care professionals in charge of adult vaccination. Hum Vaccin 2011; 7:197-201.

103. Greer AL, Fisman DN. Keeping vulnerable children safe from pertussis: preventing nosocomial pertussis transmission in the neonatal intensive care unit. Infect Control Hosp Epidemiol 2009; 30:1084-9.

104. Pascual FB, McCall CL, McMurtray A, Payton T, Smith F, Bisgard KM. Outbreak of pertussis among healthcare workers in a hospital surgical unit. Infect Control Hosp Epidemiol 2006; 27:546-52.

105. Kurt TL, Yeager AS, Guenette S, Dunlop S. Spread of pertussis by hospital staff. JAMA 1972; 221:264-7.

106. Pellini ACG, Carvalhanas TRMP, Ciccone FH, Sidi MSCJO. Investigação de casos de coqueluche na Direção Regional de Saúde XVIII - Ribeirão Preto, 2004/2005. Boletim Epidemiológico Paulista 2005; 18:1-8.

107. Beytout J, Launay O, Guiso N, Fiquet A, Baudin M, Richard P, et al. Safety of Tdap-IPV given one month after Td-IPV booster in healthy young adults: a placebo-controlled trial. Hum Vaccin 2009; 5:315-21.

108. Larnaudie S, Guiso N, Baptiste C, Desaint C, Desforges L, Lebon P, et al. Humoral immunity of DTaP-IPV vaccine (REPEVAX®) administered one month after dT-IPV vaccine (REVAXIS $®$ ) in adults with unknown vaccination history. Hum Vaccin 2010; 6:829-34.

109. Vesikari T, Van Damme P, Lindblad N, Pfletschinger U, Radley D, Ryan D, et al. An open-label, randomized, multicenter study of the safety, tolerability, and immunogenicity of quadrivalent human papillomavirus (types 6/11/16/18) vaccine given concomitantly with diphtheria, tetanus, pertussis, and poliomyelitis vaccine in healthy adolescents 11 to 17 years of age. Pediatr Infect Dis J 2010; 29:314-8.

110. Barreto L, Guasparini R, Meekison W, Noya F, Young L, Mills E. Humoral immunity 5 years after booster immunization with an adolescent and adult formulation combined tetanus, diphtheria, and 5-component acellular pertussis vaccine. Vaccine 2007; 25:8172-9. 
111. Bailleux F, Coudeville L, Kolenc-Saban A, Bevilacqua J, Barreto L, André P. Predicted long-term persistence of pertussis antibodies in adolescents after an adolescent and adult formulation combined tetanus, diphtheria, and 5-component acellular pertussis vaccine, based on mathematical modeling and 5-year observed data. Vaccine 2008; 26:3903-8.

112. Coudeville L, van Rie A, Andre P. Adult pertussis vaccination strategies and their impact on pertussis in the United States: evaluation of routine and targeted (cocoon) strategies. Epidemiol Infect 2008; 136:604-20.

113. Scott LJ. Tdap5 vaccine (Covaxis): a review of its use as a single-booster immunization for the prevention of tetanus, diphtheria, and pertussis in children (aged 4 years), adolescents, and adults. BioDrugs 2010; 24:387-406.

114. Centers for Disease Control and Prevention. Updated recommendations for use of tetanus toxoid, reduced diphtheria toxoid and acellular pertussis vaccine (Tdap) in pregnant women and persons who have or anticipate having close contact with an infant aged $<12$ months. Advisory Committee on Immunization Practices (ACIP), 2011. MMWR Morb Mortal Wkly Rep 2011; 60:1424-6.

115. Van Damme P, McIntyre P, Grimprel E, Kuriyakose S, Jacquet JM, Hardt K, et al. Immunogenicity of the reduced-antigen-content dTpa vaccine (Boostrix(®)) in adults 55 years of age and over: a subanalysis of four trials. Vaccine 2011; 29:5932-9.

116. Moro PL, Yue X, Lewis P, Haber P, Broder K. Adverse events after tetanus toxoid, reduced diphtheria toxoid and acellular pertussis (Tdap) vaccine administered to adults 65 years of age and older reported to the vaccine adverse event reporting system (VAERS), 2005-2010. Vaccine 2011; 29:9404-8.
117. Halperin SA, McNeil S, Langley J, Blatter M, Dionne M, Embree J, et al. Tolerability and antibody response in adolescents and adults revaccinated with tetanus toxoid, reduced diphtheria toxoid, and acellular pertussis vaccine adsorbed (Tdap) 4-5 years after a previous dose. Vaccine 2011; 29:8459-65.

118. Tomovici A, Barreto L, Zickler P, Meekison W, Noya F, Voloshen T, et al. Humoral immunity 10 years after booster immunization with an adolescent and adult formulation combined tetanus, diphtheria, and 5-component acellular pertussis vaccine. Vaccine 2012; 30:2647-53.

119. Halperin SA, Scheifele D, De Serres G, Noya F, Meekison W, Zickler P, et al. Immune responses in adults to revaccination with a tetanus toxoid, reduced diphtheria toxoid, and acellular pertussis vaccine 10 years after a previous dose. Vaccine 2012; 30:974-82.

120. Talbot EA, Brown KH, Kirkland KB, Baughman AL, Halperin SA, Broder KR. The safety of immunizing with tetanus-diphtheria-acellular pertussis vaccine (Tdap) less than 2 years following previous tetanus vaccination: experience during a mass vaccination campaign of healthcare personnel during a respiratory illness outbreak. Vaccine 2010; 28:8001-7.

Submitted on 09/Jul/2012

Final version resubmitted on $17 / \mathrm{Feb} / 2013$

Approved on 14/Mar/2013 